\title{
DeVelopment of PeER Teaching SuPPorted Design for X Modules for Senior EngINeERING Design Projects
}

\author{
Grant McSorley \\ School of Sustainable Design Engineering, University of Prince Edward Island \\ gmcsorley@upei.ca
}

\begin{abstract}
This paper presents initial results from a series of modules introducing Design for $X$ ( $D f X)$ concepts to student project teams. DfX methods are recognised as a means to facilitate decision making throughout the design process and directly support the "Design" graduate attribute as defined by the Canandian Enginering Accreditation Board.

In this senior design course, third and fourth year students are integrated into the same project teams, with the aim of promoting peer learning and leadership. Therefore, a flipped classroom approach was applied to the modules, followed by team-based reflection and discussion after which the appropriate DfX methods were to be applied within the projects. In the second semester third year students from each team were required to update the class on how these methods had been implemented in their projects.

Preliminary results show active participation by the fourth year students, with varying levels of application of the tools within the projects. This paper will present specific examples of student led discussion and exercises surrounding $D f X$ topics, as well as a qualitative evaluation of the application of DfX methods by the student teams. Recommendations for future improvement include the development of additional short duration, concrete, formative DfX activities for inclusion in the modules.
\end{abstract}

Keywords: design for $\mathrm{x}$, peer learning, engineering education, project-based learning.

\section{INTRODUCTION}

Project-based learning has become a common strategy for exposing engineering students to the complexities of the engineering profession by requiring them to develop solutions to realistic, open-ended problems. Project-based learning is also seen as an effective means for developing within students the graduate attributes identified by professional engineering associations. In Canada, these are codified in Canadian Engineering Accreditation
Board's list of Graduate Attributes [1], which include the "Design" attribute, defined as:

"An ability to design solutions for complex, openended engineering problems and to design systems, components or processes that meet specified needs with appropriate attention to health and safety risks, applicable standards, economic, environmental, cultural and societal considerations."

This attribute in particular is targeted by the inclusion of engineering design projects in the engineering curriculum. However, the development of this attribute requires advanced critical thinking and decision making skills, as well an ability to synthesize information across a broad range of topics, which is not easy for even experienced engineers. To support students in this area, a series of Design for $\mathrm{X}$ (DfX) modules have been developed and implemented as part of the fourth year engineering design curriculum at the School of Sustainable Design Engineering of the University of Prince Edward Island. Design for X (DfX) methods are recognized as a means to facilitate decision making throughout the design process through the consideration of the requirements of various domains, the latter epresented by " $X$ " [2]. These include, but are not limited to, design for:

(i) Manufacturing and Assembly

(ii) Reliability

(iii) Quality

(iv) Sustainability

The focus of this paper is the development and implementation these modules meant to encourage peer teaching and learning, as well as the application of design tools to complex engineering design problems. Preliminary results have shown an active participation by the fourth year students, with varying levels of application of the tools within the projects. This paper will present specific examples of student led discussion and exercises surrounding DfX topics, and a qualitative evaluation of 
the application of the material to their projects and the transfer of knowledge through peer learning. Recommendations for future improvement and strategies will also be discussed.

\section{BACKGROUND}

\subsection{Design for $X$ methods}

Design for $\mathrm{X}$ (DfX) methods are recognised as a means to facilitate decision making throughout the design process. The concept of DfX originated with Boothroyd and Dewhurst's development of Design for Assembly (DfA) in the $1970 \mathrm{~s}$, where they defined a set of assembly constraints which should be taken into account during the design process. Since then, this field has expanded to include various topics such as Design for Quality, Design for the Environment, Design for Life Cycle Costs, Design for Disassembly, Design for Recyclability etc... [2-4]. This expansion of DfX is due to the realization that an increasing range of life cycle issues and their specific constraints should be taken into account during design.

It is generally accepted that decisions taken early in the design process can have a significant impact on the lifecycle cost of a product, with some estimates ranging from $70 \%$ to $80 \%$ of lifecycle costs being determined before the design is complete [5]. For example, a decision which later turns out to negatively impact a product's reliability can have a large impact on total lifecycle costs. Frequently, these problems are only identified after a significant amount of resources have been committed to a project, making late stage changes costly and complex to implement. Therefore, it is critical that DfX methods be applied early in the design process when iterations are relatively cheap. In this way, the most appropriate tools and activities can be identified early in the project, and a strategy can be developed for their subsequent deployment $[2,5,6]$.

\subsection{Peer Teaching in Engineering Design}

Peer learning, where knowledge is acquired through interaction with colleagues of equal or matched status has been shown to have positive effects on both the student and the teacher. Peer teaching, sometimes referred to as peer tutoring and closely related to the flipped classroom, is a particular form of peer learning where those interacting take on explicit roles of teacher and student. This is in contrast to mentoring, where a more experienced individual takes on the role of providing positive reinforcement and acts as role model, and to cooperative learning, where individuals of equal experience are put in a position of learning in parallel and supporting each other through the process [7].
Peer teaching has also been shown to promote deeper understanding by the teacher of the information being presented, as well as promoting communication skills [8], which is another of the CEAB Graduate Attributes. Closely related to peer teaching is the flipped classroom approach where instead of the instructor providing classroom instruction, an individual or group of students prepares and teaches, or transfers knowledge, to another group of students [9]. There are normally core concepts that must be understood and explained from one individual or group to another individual or group of students.

\section{METHODOLOGY}

\subsection{Course Structure}

Along with the development of engineering design abilities, a common goal of senior engineering design projects is the development of leadership and teamwork abilities. To encourage this, the Senior Engineering Design project and Professional Practice course at the University of Prince Edward Island School of Sustainable Design Engineering (SSDE) is completed in teams composed of fourth year project leads and third year team members. This places the fourth year students in a situation where they are required to provide mentorship and leadership for their teams.

\subsection{DfX Modules}

To promote the development of students' abilities to consider multiple competing factors in their decisions making process, three DfX modules were implemented in the Senior Engineering Design project and Professional Practice course: Design for Manufacturability, Design for Reliability and Design for Sustainability.

In order to encourage peer teaching a flipped classroom approach was used, where individual students prepared exercises and discussion material based on previously provided readings and examples. The emphasis of these discussions was the application of domain specific design methods and/or domain specific case studies.

\subsection{Application of DfX methods}

Following the modules, fourth year students were required to share the information with their third year team mates in order for the team to apply appropriate methods to their specific projects. While it was recognized that specific methods would apply to varying degrees to each project, it was left to the students to consider how the concepts applied to their projects and to justify their strategies. 
To track their progress and to expose the teams to alternative implementation strategies, in the second semester the teams were required to update the class on how two of these concepts, design for sustainability and design for reliability, were applied to their projects. It was also required that the presenter be a third year student. The objective was to promote an exchange of information between project leads and members, requiring the team lead to work with the team to ensure that all members had at least a basic understanding of the application of the relevant DfX concepts.

Finally, throughout the project the students submitted five design updates in the form of reports and presentations. As part of these reports, students were required to present how they had addressed the sustainability, ease of manufacturing and assembly, reliability and safety of their designs throughout their project.

\section{RESULTS AND DISCUSSION}

In order to assess the initial effectiveness of this approach to teaching DfX concepts, a qualitative, descriptive approach was taken. In this section, examples of the results of each activity will be presented, along with instructor observations and student reflections, where applicable.

\subsection{Student DfX Presentations}

The relative level of engagement during the flipped classroom DfX modules was judged to be quite high, with positive feedback received and active participation in discussions. While students took different approaches to engaging their peers with the material, the three DfX modules were judged to be relatively successful.

For design for sustainability, the student chose to present current technology for smart, energy efficient homes, but focused the discussion on the concern of greenwashing, the misapplication of environmental standards and the role of engineers in avoiding this.

For design for manufacturing, the student drew on his personal experience with local manufacturing companies and design for manufacturing best practices such as avoiding handed, asymmetrical parts and the importance of frequent consultation with manufacturing experts regarding process capabilities. Following this, the group was led in the evaluation of the ease of manufacturing and assembly for the SAE BAJA dune buggy, which multiple class members had helped design.

Finally, for design for reliability, the student's focus was the application of Failure Modes and Effects Analysis. Although there was some confusion between a Process FMEA and a Design FMEA, the process was clearly explained. This concept was also applied to the design of the UPEI SAE Baja through a group exercise.
In two of three cases, the students led the group through concrete DfX techniques, while in the case of sustainability the focus was a qualitative consideration of the issues and possible trade-offs or contradictions. This mirrors both the literature, where design for sustainability and the environment are seen as difficult to quantify [10], and the subsequent application of the concepts within the projects, which will be discussed in the following sections.

\subsection{Team DfX Presentations}

The focus of the second semester DfX presentations to the entire class during the two allotted classes were design for sustainability and design for reliability.

In terms of sustainability, similar to the conceptual nature of the fourth year student's presentation, most considerations were qualitative, with only one team proposing the future use of a software-based decision aid for sustainable material selection. While every team demonstrated a conceptual understanding of sustainability, they demonstrated little ability to make structured decisions regarding the sustainability of their designs. Typically, this was expressed as a vague guiding principle, for example to reduce waste and increase efficiency, without quantification. Furthermore, it was difficult for several teams to differentiate between the overall sustainable nature of their projects (e.g. installation of solar panels required by client) and the sustainability of their design decisions (e.g. selection of environmentally benign construction materials for installation).

The subsequent presentations regarding reliability were much more encouraging. Five of seven teams discussed concrete design decisions that were taken to improve reliability of their designs and were able to justify these when questioned. In one case, a team had completed a system level FMEA and was in the process of completing the same at the component level. In another, a systematic evaluation of proposed modifications to a client's facility was carried out in order to mitigate any adverse effects on system reliability. In only two cases was the concept misunderstood, for example conflating the reliability of the design with the reliability or repeatability of experimental data.

\subsection{Application of DfX Methods in Design Projects}

As was expected, the application of the DfX methods within the projects evolved throughout the course. Looking only at the reports, table 1 shows the number of teams (out of seven) who explicitly addressed the three DfX topics at the conceptual design stage during the first 
semester, and in their final reports at the end of the second semester. In each case, a substantial increase is noted.

Table 1. Number of teams addressing DfX topics across project phases

\begin{tabular}{|c|c|c|}
\cline { 2 - 3 } \multicolumn{1}{c|}{} & $\begin{array}{c}\text { Concept } \\
\text { Development }\end{array}$ & $\begin{array}{c}\text { Project } \\
\text { Close-out }\end{array}$ \\
\hline Sustainability & 3 & 6 \\
\hline Reliability & 3 & 7 \\
\hline Manufacturability & 2 & 5 \\
\hline
\end{tabular}

This was not only a question of semantics, but a clear progression was seen in terms of the team's abilities to justify the decisions made and to explicitly explain their design rationale. That being said, the three DfX domains in question were presented to varying levels of success.

The most concrete considerations remained those pertaining to reliability, as the primary focus of most teams was product functionality, which is directly impacted by its reliability. This was typically addressed through component selection based and prototype verification, with only one team completing an FMEA. While these are valid approaches, a more systematic analysis of critical components is a future objective.

There was a noted increase in addressing design for manufacturing and assembly as the project progressed. This manifested itself in two ways. The first was through prototyping, where teams encountered first-hand the difficulty of moving from digital design definitions to the physical construction of their products. Second, consultation with school technical staff provided invaluable feedback on whether it would be possible to manufacture and assemble the student designs. This led to many teams passing through multiple design iterations to ensure the quality of the physical product. In the future, a key recommendation is to introduce physical prototyping and interactions with technicians earlier in the project to encourage additional iterations and to able to resolve manufacturing and assembly issues beginning at the conceptual design stage.

Design for sustainability remained the least welldefined area. At the end of the project, while teams had considered certain qualitative measures of sustainability, no team had completed a systematic analysis of the sustainability of their designs. Rather, teams relied mainly on subjective criteria, personal judgment and research to justify the sustainability of their designs. Typically this was restricted to statements such as:

"Being able to minimize the amount of material
required throughout the entire design process
through this material selection improves the
sustainability associated with the design."
"The tank-less hot water heater was deemed best suited for this application due to its energy efficient design. [The manufacturer] claims to have an energy efficiency of $99.8 \%$, while also reducing space and heat losses by not having a reserve tank."

While these are valid considerations for incremental increases in sustainability, they do not indicate detailed analysis and critical thinking. However, this is not completely surprising. In comparison to manufacturing and reliability, sustainability can be seen as less tangible, and hence more difficult to grasp by students. Unlike manufacturing, which can be evaluated in terms of time and precision, or reliability, which can be measured in terms of probability, it is difficult to set a standard measure for sustainability. Attempts to resolve this include the calculation of equivalent $\mathrm{CO} 2$ emissions or a human toxicity index, however these are difficult to interpret and to compare to one another. Furthermore, the concepts of environmental impact assessments and life cycle analysis are not as common within the engineering curriculum as manufacturing and reliability.

One strategy being considered to address this is the introduction of a more detailed sustainable engineering course earlier in the curriculum. However, from the point of view of this course, a potential solution is to introduce an additional hands-on module using dedicated environmental analysis software.

It should also be noted that while the initial intent of the work presented here was to implement a peer teaching environment for the introduction of DfX, first in the use of the flipped classroom and later in having project leads present the concepts to the other team members, this was not the only form of peer learning seen in the projects. As the team leads were not experts themselves in DfX methods, they also carried out cooperative learning [11], working first with each other and later with their teammates to develop a common understanding of the methods.

\section{CONCLUSION}

This paper has presented observations and qualitative findings concerning a first iteration of DfX modules being taught within the context of a senior engineering design project. These modules were implemented through a flipped classroom approach, as well as peer teaching. The overall objective was to support the development of the Design graduate attribute.

Initial results suggest an improvement throughout the project in terms of justifying design decisions using domain specific tools and rationale. This aligns well with the targeted graduate attribute in so far as promoting the consideration of complex factors when making design 
decisions. However, many of the justifications presented by the students are subjective or qualitative.

It is proposed that for future iterations, activities be included where students apply DfX methods to relatively direct sample problems in order to quickly expose them to possible methods and provide feedback on their use. Furthermore, in a separate design course activity, the fourth year students, as a group, facilitated a computer assisted design and engineering lab for the third year students which was well received with a high level of engagement. This may be a more effective means of facilitating peer learning than the separate team-based activities presented this year.

\section{References}

[1] Canadian Engineering Accreditation Board, 2016 Accreditation Criteria and Procedures. Canada: Engineers Canada, 125 pp., 2016. \{ISSN 1708-8054\} Available as of May 7, 2017 from https://engineerscanada.ca/sites/default/files/accreditationcriteria-procedures-2016-final.pdf

[2] Tsai-C Kuo, Samuel H. Huang and Hong-C Zang, "Design for manufacture and design for ' $\mathrm{X}$ ': concepts, applications, and perspectives," Computers \& Industrial Engineering, vol. 2001, no. 41, pp. 241-260, 2001.

[3] Benjamin S. Blanchard and Wolter J. Fabrycky, Systems Engineering and Analysis. Upper Saddle River: Prentice Hall, 2006, 804 pp.

[4] Karl T. Ulrich and Steven D. Eppinger, Product design and development. Toronto: McGraw-Hill, 2008 ( $4^{\text {th }}$ ed.), 368 pp. \{ISBN: 007229647\}

[5] Koichi Ohtomi, "Importance of upstream design in product development and its methodology," in Proc. Thermal, Mechanical and Multi-Physics Simulation and Experiments in Micro-Electronics and Micro-Systems Conf., EuroSimE 2005 (Berlin, DE; 18-26 April 2005), pp. 17-18, 2005.

[6] Klaus Ehrlenspiel, Alfons Kiewert and Udo Lindemann, Cost-efficient Design. New York, N.Y.: American Society of Mechanical Engineers, 2007, 544 pp. \{ISBN: 9780791802507\}

[7] K.J. Topping, "Trends in Peer Learning," Educational Psychology, vol. 25, no. 6, pp. 631-645, 2005. Available as of May 7, 2017 from

http://dx.doi.org/10.1080/01443410500345172

[8] Shri Ramaswamy, Ilene Harris and Ulrike Tschirner, "Student Peer Teaching: An Innovative Approach to Instruction in Science and Engineering Education," Journal of Science Education and Technology, vol. 10, no. 2, pp. 165-171, 2001. Available as of May 7, 2017 from https://link-springercom.proxy.library.upei.ca/article/10.1023/A:1009421231056

[9] Catherine H. Crouch and Eric Mazur, "Peer Instruction: Ten years of experience and results," American Journal of Physics, vol. 69, no. 9, pp. 970-977, 2001. Available as of May 7, 2017 from http://dx.doi.org/10.1119/1.1374249

[10] Timothy C. McAloone, "To what extent are DFX principles really used when developing environmentally sensitive products?" in Proc. 9th Symposium Fertigungsgerechtes Konstruieren (Schnaittach, DE; 15-16 November 1998), 7 pp., 1998.

[11] David W. Johnson and Roger T. Johnson, "An Educational Psychology Success Story: Social Interdependence Theory and Cooperative Learning," Educational Researcher, vol. 38, no. 5, pp. 365-379, 2009. Available as of May 7, 2017 from http://www.jstor.org/stable/20532563 